\title{
Pediatric flexor tendon injuries: A 10-year outcome analysis
}

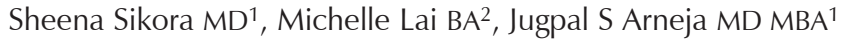

S Sikora, M Lai, JS Arneja. Pediatric flexor tendon injuries: A 10-year outcome analysis. Can J Plast Surg 2013;21(3):181-185.

BACKGROUND: Primary flexor tendon repair was first

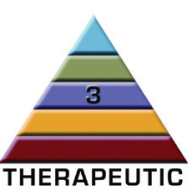

introduced in the 1960s. Since then, major advances in the understanding of flexor tendon anatomy and biology have led to improved outcomes following repair. Relative to the adult population, sparse knowledge exists as to which operative and postoperative treatments are most successful in children. This is due, in part, to the rarity of pediatric tendon lacerations compared with the adult population, but also related to challenges when working with smaller anatomy and the decreased compliance in children with respect to rehabilitation protocols. Published reports indicate that the incidence of 'good' flexor tendon repair outcomes is as low as 53\%.

OBJECTIVE: To determine the injury pattern and demographics of pediatric flexor tendon injuries involving zones I, II and III over the past decade, and to report results and identify treatment paradigms that are associated with optimal outcomes.

METHODS: A retrospective chart review of all flexor tendon injuries involving zones I, II and III between April 2001 and December 2010 was performed. Parameters reviewed included demographics, injury mechanism, repair technique, outcomes and complications.

RESULTS: A total of 47 patients with a median age of eight years experienced 100 tendon injuries. The most common cause of injury was glass $(n=22)$, with the most common digit injured being the small finger $(n=30)$. Tendon injuries included the following: flexor digitorum superficialis $(n=46)$; flexor digitorum profundus $(n=45)$, flexor pollicis longus $(\mathrm{n}=8)$; and adductor pollicis longus $(\mathrm{n}=1)$. Zone III had the highest number of injuries $(n=47)$, followed by zone II $(n=39)$. Ninety tendons were repaired using polyester suture, the most common size being 4-0. The modified Kessler technique was used in the majority of cases $(n=62)$. Only 22 tendons underwent an epitendinous repair. Splint immobilization was used in 30 patients and a full cast in 17. The median duration of immobilization was four weeks. Forty-two patients underwent postoperative hand therapy. Using the American Society for Surgery of the Hand Total Active Motion (TAM) score, 40 of 47 patients experienced $100 \%$ recovery with no functional limitations. Two patients had a score $<100 \%$, not necessitating further surgery. A second operation was required for five patients. All patients in this group demonstrated 100\% TAM at one year. CONCLUSION: Pediatric flexor tendon injuries remain rare and usually involve the dominant hand holding or manipulating an object. An excellent outcome was found in $95.9 \%$ of patients assessed by TAM scores. Repair technique was chosen according to the size of tendon involved. Patients not treated with hand therapy and not immobilized in a cast were often too young to participate in rehabilitation. Based on the results, immobilization of young children for four weeks is safe and does not worsen functional outcomes. Of the patients requiring a second procedure, no predictive variables for poorer outcomes were found on analysis of age, outcome, cause, location, repair technique, rehabilitation protocol or zone of injury.

Key Words: Flexor tendon; Injury; Outcomes; Pediatric

\section{Les blessures du tendon fléchisseur en pédiatrie : une analyse d'issue sur dix ans}

HISTORIQUE : La réparation primaire du tendon fléchisseur a été utilisée pour la première fois dans les années 1960. Depuis, la compréhension de l'anatomie et de la biologie du tendon fléchisseur a énormément progressé, ce qui a favorisé de meilleures issues. Par rapport à la population adulte, on ne sait pas vraiment quels traitements opératoires et postopératoires fonctionnent le mieux chez les enfants. Ce phénomène est partiellement attribuable au peu de lacérations du tendon en pédiatrie par rapport à la population adulte, mais également à la difficulté de travailler sur une plus petite anatomie et à la moins bonne adhésion des enfants aux protocoles de réadaptation. Selon des rapports publiés, l'incidence de réparations du tendon fléchisseur ayant une incidence positive n'atteindrait pas plus de $53 \%$.

OBJECTIF : Déterminer le profil des blessures et les caractéristiques démographiques des patients d'âge pédiatrique présentant une blessure du tendon fléchisseur des zones I, II et III depuis dix ans, rendre compte des résultats et décrire les paradigmes thérapeutiques associés aux issues optimales.

MÉTHODOLOGIE : Les chercheurs ont effectué une analyse rétrospective des dossiers de toutes les blessures des zones I, II et III du tendon fléchisseur entre avril 2001 et décembre 2010. Les paramètres qu'ils ont analysés sont les caractéristiques démographiques, le mécanisme de blessure, la technique de réparation, les issues et les complications.

RÉSULTATS : Au total, 47 patients ayant un âge médian de huit ans ont subi 100 blessures du tendon, surtout causées par du verre $(n=22)$ et touchant le petit doigt $(n=30)$. Les blessures du tendon s'établissaient comme suit : fléchisseur commun superficiel $(\mathrm{n}=46)$, fléchisseur commun profond $(\mathrm{n}=45)$, long fléchisseur du pouce $(\mathrm{n}=8)$ et long adducteur du pouce $(\mathrm{n}=1)$. Le plus grand nombre de blessures s'observait sur la zone III $(n=47)$, suivi de la zone II $(\mathrm{n}=39)$. Quatre-vingt-neuf tendons ont été réparés à l'aide d'une suture de polyester, généralement de dimension 4-0. Dans la majorité des cas, les chirurgiens ont privilégié la technique de Kessler modifiée $(n=62)$. Seulement 22 tendons ont subi une réparation épitendineuse. Trente patients ont été immobilisés au moyen d'une attelle, et 17, au moyen d'un plâtre complet, pendant une durée médiane de quatre semaines. Quarante-deux patients ont subi une thérapie postopératoire de la main. Selon l'indice de mouvement actif total de la main (TAM) de l'American Society for Surgery, 40 des 47 patients ont présenté un rétablissement complet, sans limites fonctionnelles. Deux patients ont présenté un indice inférieur à 100 \%, qui n'a toutefois pas nécessité d'autre opération. Cinq patients ont dû subir une deuxième opération. Tous les patients de ce groupe présentaient un indice de TAM de $100 \%$ au bout d'un an.

CONCLUSION : Les blessures du tendon fléchisseur demeurent rares en pédiatrie et touchent généralement la main dominante qui tient ou manipule un objet. D'après l'indice TAM, 95,9 \% des patients évalués ont présenté une excellente issue. La technique de réparation était sélectionnée selon la dimension du tendon touchée. Les patients qui ne subissaient pas de thérapie de la main et qui n'étaient pas immobilisés dans un plâtre étaient souvent trop jeunes pour participer à la réadaptation. D'après les résultats, l'immobilisation des jeunes enfants pendant quatre semaines est sécuritaire et n'empire pas les issues fonctionnelles. Chez les patients qui ont besoin de subir une deuxième intervention, les chercheurs n'ont pas obtenu de variables prédictives d'issues plus négatives à l'analyse de l'âge, de l'issue, de la cause, du foyer, de la technique de réparation ou de la zone de blessure.

\footnotetext{
${ }^{1}$ Division of Plastic Surgery, British Columbia Children's Hospital and University of British Columbia; ${ }^{2}$ Faculty of Medicine, University of British Columbia, Vancouver, British Columbia

Correspondence: Dr Jugpal S Arneja, British Columbia Children's Hospital, Division of Plastic Surgery, A237 Shaughnessy Building, Box 150 , 4480 Oak Street, Vancouver, British Columbia V6H 3V4. Telephone 604-875-2794, fax 604-875-2749, e-mail jugpal.arneja@ubc.ca
} 
$P^{\mathrm{r}}$ rimary tendon repair following injury was first introduced in the 1960s. Since then, significant advances in the understanding of flexor tendon anatomy and biology have led to improved outcomes following repair (1). Relative to the adult population, there is sparse knowledge as to which operative and postoperative treatments are most successful in children. This is due, in part, to the rarity of pediatric tendon lacerations compared with the adult population. A recent study found the incidence of flexor tendon injury in children to be 0.036 per 1000 , with a peak incidence at three years of age (2). Glass and knife lacerations were the most common causes of injury (2). These injuries are severe and, if managed inadequately, can result in loss of hand function. Published reports indicate that the incidence of 'good' flexor tendon repair outcomes are as low as 53\% (1).

Methods to treat flexor tendon lacerations in children are not identical to those used in adults. Factors such as the smaller size of the pediatric tendon and reduced postoperative compliance in children influence the techniques that can be selected. In adults, increasing the number of strands across a tendon repair has been shown to improve function, reduce time to initiation of therapy and decrease complications. In contrast, a study comparing two-strand and four-strand techniques in children showed no difference in range of motion or rupture rates (3).

Postsurgical rehabilitation programs have been shown to significantly decrease scarring and adhesions in adults (4). Despite this, data involving children remain unclear, with some studies showing no difference between early rehabilitation protocols and four weeks of cast immobilization (5). Rehabilitation protocols, such as the Kleinert, are beneficial in children older than six years of age, but these protocols are difficult to use in younger children $(1,2,6)$. Some studies claim that protocols are not necessary in children younger than six years of age, and that only immobilization is required $(5,7)$. Others have shown that immobilization for longer than four weeks causes functional decline $(8,9)$. In addition, more invasive programs have been trialed including injection of botulinum toxin into the flexor muscles and suturing of the fingertip to the palmar skin to prevent tendon rupture (10). However, presently, there is no 'gold standard' rehabilitation protocol for children with flexor tendon injuries.

The purpose of the present study was to review the demographics and events surrounding pediatric flexor tendon injuries, and to examine methods of repair and rehabilitation that have led to both positive and negative outcomes over a 10-year interval at British Columbia Children's Hospital (BCCH), Vancouver, British Columbia.

\section{METHODS}

University of British Columbia/Children's and Women's Health Centre of British Columbia Research Ethics Board approval (H1100500) was obtained to conduct the present research. A retrospective review of all patients treated at BCCH from April 2001 to December 2010 was performed. Subjects were identified using a key word search in the $\mathrm{BCCH}$ medical records database using the names/abbreviations of flexor tendons injured as well as the names of plastic surgeons at $\mathrm{BCCH}$ within the 10 -year period. All pediatric patients $(<17$ years of age) who underwent flexor tendon repair within zones I, II and III by plastic surgeons at $\mathrm{BCCH}$ were included. Patients with amputated structures, injuries involving extensor tendons, and charts with incomplete data or insufficient follow-up were excluded.

Data points reviewed included basic patient demographics such as sex, race, age at injury and surgical treatment. Clinical characteristics noted at presentation included comorbid medical conditions, previous or existing injuries to the involved hand, and the location and type of involved tendon, bone, vessel or nerve. An analysis of surgery and injury-related parameters and rehabilitation included the following: flexor tendon laceration presentation as a function of location of tendon; cause of laceration; type of repair; type of suture; method of postoperative immobilization and/or rehabilitation; age of patient; and sex. Additional parameters reviewed included surgical technique, any previous injuries or surgeries to the involved extremity, and immediate postoperative and long-term outcomes.
Patients' range of motion of the digit and surgical complications in the postoperative period were recorded. Functional outcome was calculated using the American Society for Surgery of the Hand Total Active Motion (TAM) score, first described by Strickland and Glogovac in 1980 (9), and is recorded as a percentage of normal range of motion. The scores are then further categorized into groups, with excellent results defined as a score of $75 \%$ to $100 \%$ of normal; good results defined as $50 \%$ to $74 \%$ of normal; fair results are $25 \%$ to $49 \%$ of normal; and poor results are $<25 \%$ of normal. Patients with incomplete follow-up were telephoned to enquire about any postoperative rehabilitation and hand function. Simple questions asked over the telephone were used to calculate a TAM score.

\section{RESULTS}

One hundred tendon repairs were completed in 47 pediatric patients at BCCH between April 2001 and December 2010. The median patient age was 96 months (range 14 to 192 months) and 33 patients were male. The median time between injury and repair was zero days (range zero to 31 days). Injuries involving the right hand occurred in 32 patients. One patient experienced bilateral injuries. The most common cause of injury was glass (22 patients) followed by knife (11 patients). Table 1 summarizes the pertinent demographic data.

Per patient, the median number of fingers involved was one, with a range of 0 to 4 (mean 1.24). The median number of tendons involved per patient was 1.79 (range one to six). Only eight patients had multiple tendon involvement. The most common digit injured was the index finger (31 tendons), followed by the small finger (30 tendons), ring finger (19 tendons), middle finger (17 tendons) and thumb (three tendons). There were 95 complete tendon lacerations, four partial lacerations and one tendon avulsion. Zone III had the greatest number of injuries $(n=42)$, followed by zone II $(n=39)$. The flexor digitorum superficialis (FDS) was found to be lacerated in 46 of 100 tendon injuries. Flexor digitorum profundus (FDP) lacerations were found in 45 of 100 tendon injuries followed by flexor pollicis longus (eight of 100) and abductor pollicis longus (one injury). Table 2 summarizes the relevant injury data.

The most common repair method chosen was the modified Kessler (62 tendon repairs) followed by the figure-of-eight (26 tendon repairs). A cruciate repair was used in five tendons, a horizontal mattress repair was used in four tendons, a modified Kleinert in two tendons and a Kessler repair in one tendon. Polyester was the suture of choice to repair 90 tendons, followed by nylon, prolene and vicryl (five, four and one tendons, respectively). The most common suture size ( 84 tendon repairs) was 4-0, followed by 5-0, 3-0, 2-0 and 6-0 (eight, four, two and two tendons, respectively). Of a total 100 tendons, only 22 received an epitendinous repair. The most common suture chosen was nylon, followed by polyester and prolene (13, five and four tendons, respectively). The most common size of suture was 6-0 (18 tendons) followed by 7-0 (two tendons) then 5-0 and 3-0 (one and one, respectively). Postoperative immobilization varied: 17 patients were immobilized in a circumferential cast with the remainder $(n=30)$ receiving a dorsal splint. The median length of complete immobilization was four weeks (range 0.5 to 24 weeks). Forty-two of 47 patients received postoperative hand therapy from either a physiotherapist or a home hand therapy program. Table 2 summarizes the relevant injury, surgery and rehabilitation results.

Using TAM scores, 42 of 47 patients had excellent results (TAM = $100 \%)$. Two patients received a score $<100 \%$. The first patient was an eight-year-old boy who had a zone II complete FDP laceration of his left ring finger from glass. His range of motion post-operatively resulted in a TAM score of $68.3 \%$, placing him in the category of a 'good' result. Because the patient's function was not inhibited, the family decided not to proceed with additional surgery. The second patient was also an eight-year-old boy who experienced a complete zone I FDP laceration to the left small finger by a knife. One year postinjury, he maintained a 'good' outcome, with a TAM score of $68.6 \%$ and was not interested in further surgery. 
TABLE 1

Patient demographic data

\begin{tabular}{|c|c|c|c|c|}
\hline & \multirow[b]{2}{*}{ Overall } & \multicolumn{2}{|c|}{ ASSH TAM $100 \%$} & \multirow{2}{*}{$\begin{array}{c}\text { ASSH TAM } \\
<100 \%\end{array}$} \\
\hline & & 1 operation & 2 operations & \\
\hline Total, $\mathrm{n}$ & 47 & 40 & 5 & 2 \\
\hline Male & $33(70)$ & $28(70)$ & $3(60)$ & $2(100)$ \\
\hline Female & $14(30)$ & $12(30)$ & $2(40)$ & $0(0)$ \\
\hline Total tendons, $\mathrm{n}$ & 100 & 85 & 13 & 2 \\
\hline Age, months, mean & 100.58 & 99.08 & 133.6 & 96 \\
\hline $\begin{array}{l}\text { Time between } \\
\text { injury and (first) } \\
\text { repair, days, } \\
\text { mean }\end{array}$ & 1.7 & 1.71 & 1.4 & 1 \\
\hline \multicolumn{5}{|l|}{ Hand(s) } \\
\hline Right & $32(68)$ & $28(70)$ & $4(80)$ & $0(0)$ \\
\hline Left & $14(30)$ & $11(28)$ & $1(20)$ & $2(100)$ \\
\hline Bilateral & $1(2)$ & $1(2)$ & $0(0)$ & $0(0)$ \\
\hline \multicolumn{5}{|l|}{ Mechanism of injury } \\
\hline Glass & $22(47)$ & $20(50)$ & $1(20)$ & $1(50)$ \\
\hline Knife & $11(24)$ & $6(15)$ & $4(80)$ & $1(50)$ \\
\hline Pumpkin carving & $3(6)$ & $3(7)$ & $0(0)$ & $0(0)$ \\
\hline Other & $11(23)$ & $11(3)$ & $0(0)$ & $0(0)$ \\
\hline
\end{tabular}

Data presented as $n$ (\%) unless otherwise indicated. ASSH TAM American Society for Surgery of the Hand Total Active Motion score

Five patients required a second procedure. A median of two tendons were involved (range two to three). All patients experienced complete FDP lacerations and four of five patients had complete FDS lacerations. Three patients required tenolysis and two patients required a two-stage tendon reconstruction. The median age of these five patients was 12.83 years (range 3 to 14.92 years [36 to 179 months]). Three patients were male and two were female. Median time between injury and first repair was one day (range zero to five days). Median immobilization time was four weeks and all patients received postoperative hand therapy after their first and second procedure. One year postinjury, all patients received a TAM score of $100 \%$. Table 3 summarizes the relevant data.

\section{DISCUSSION}

Pediatric flexor tendon injuries are rare. In our catchment area of approximately four million people, there were injuries to only 100 tendons over our 120-month study interval, which corresponds to less than one tendon injury per month. To date, few prospective outcome trials have been performed, likely due to the rarity of pediatric flexor tendon injuries. Nonetheless, improper management of these cases can lead to long-term functional impairment and continued research is required.

\section{Cause of injury}

The majority of injuries in the study population involved the dominant hand. The median age of patients injured by glass was 80 months. Often this included a child falling while holding a glass in the dominant hand or running through a glass door. Knife injuries occurred in older children with a median age of 140 months. This included kitchen knives, pumpkin carving knives and self-inflicted injuries. Multiple studies have also shown glass and knife injuries to be the most common cause of tendon injuries in children $(1,2,11,12)$. It has been recommended that glass doors without safety glass should be prohibited in public buildings such as schools (2).

\section{Repair technique}

On review of the adult literature, the most commonly used core repair technique is the modified Kessler (13). It has been shown that repair strength is proportional to the number of strands across a repair site and inversely proportional to the size of the suture (13). Of course, one must take into account work of resistance and glide through the pulley mechanisms when determining the limit number of strands and suture
TABLE 2

Results: Injury, surgery and rehabilitation

\begin{tabular}{|c|c|c|c|c|}
\hline & \multirow[b]{2}{*}{ Overall } & \multicolumn{2}{|c|}{ ASSH TAM $100 \%$} & \multirow{2}{*}{$\begin{array}{l}\text { ASSH TAM } \\
<100 \% \\
\end{array}$} \\
\hline & & 1 operation & 2 operations & \\
\hline Tendons, $\mathrm{n}$, mean & 1.79 & 1.8 & 2.6 & 1 \\
\hline \multicolumn{5}{|l|}{ Finger $(n=100)$} \\
\hline D1 & $3(3)$ & $3(3)$ & $0(0)$ & $0(0)$ \\
\hline D2 & $31(31)$ & $26(33)$ & $5(38)$ & $0(0)$ \\
\hline D3 & $17(17)$ & $14(18)$ & $3(24)$ & $0(0)$ \\
\hline D4 & $19(19)$ & $14(19)$ & $4(38)$ & $1(50)$ \\
\hline D5 & $30(30)$ & $29(34)$ & $0(0)$ & $1(50)$ \\
\hline \multicolumn{5}{|l|}{ Injury type $(n=100)$} \\
\hline Complete & $95(95)$ & 85 (99) & $8(69)$ & $2(100)$ \\
\hline Partial & $4(4)$ & $0(0)$ & $4(31)$ & $0(0)$ \\
\hline Avulsion & $1(1)$ & $1(1)$ & $0(0)$ & $0(0)$ \\
\hline \multicolumn{5}{|c|}{ Zone of injury ( $n=100$ ) } \\
\hline 1 & $9(9)$ & $5(6)$ & $3(25)$ & $1(50)$ \\
\hline II & $39(39)$ & $31(36)$ & $7(58)$ & $1(50)$ \\
\hline III & $43(43)$ & $41(48)$ & $2(17)$ & $0(0)$ \\
\hline Multiple & $9(9)$ & $9(10)$ & $0(0)$ & $0(0)$ \\
\hline \multicolumn{5}{|l|}{ Tendon $(n=100)$} \\
\hline FDS & $46(46)$ & $42(48)$ & $4(39)$ & $0(0)$ \\
\hline FDP & $45(45)$ & $35(41)$ & $8(61)$ & $2(100)$ \\
\hline FPL & $8(8)$ & $8(10)$ & $0(0)$ & $0(0)$ \\
\hline APL & $1(1)$ & $1(1)$ & $0(0)$ & $0(0)$ \\
\hline \multicolumn{5}{|c|}{ Core suture technique $(n=100)$} \\
\hline Modified Kessler & $62(62)$ & $51(59)$ & $9(75)$ & $2(100)$ \\
\hline Figure of 8 & $26(26)$ & $23(27)$ & $3(25)$ & $0(0)$ \\
\hline Cruciate & $5(5)$ & $5(6)$ & $0(0)$ & $0(0)$ \\
\hline $\begin{array}{r}\text { Horizontal } \\
\text { mattress }\end{array}$ & $4(4)$ & $4(5)$ & $0(0)$ & $0(0)$ \\
\hline Modified Kleinert & $2(2)$ & $2(2)$ & $0(0)$ & $0(0)$ \\
\hline Kessler & $1(1)$ & $1(1)$ & $0(0)$ & $0(0)$ \\
\hline \multicolumn{5}{|c|}{ Core suture material $(n=100)$} \\
\hline Polyester & $90(90)$ & $76(88)$ & $12(100)$ & $2(100)$ \\
\hline Nylon & $5(5)$ & $5(6)$ & $0(0)$ & $0(0)$ \\
\hline Prolene & $4(4)$ & $4(5)$ & $0(0)$ & $0(0)$ \\
\hline Vicryl & $1(1)$ & $1(1)$ & $0(0)$ & $0(0)$ \\
\hline \multicolumn{5}{|c|}{ Core suture size $(n=100)$} \\
\hline $2-0$ & $2(2)$ & $2(2)$ & $0(0)$ & $0(0)$ \\
\hline $3-0$ & $4(4)$ & $4(5)$ & $0(0)$ & $0(0)$ \\
\hline $4-0$ & $84(84)$ & $72(84)$ & $10(83)$ & $2(100)$ \\
\hline $5-0$ & $8(8)$ & $6(7)$ & $2(17)$ & $0(0)$ \\
\hline $6-0$ & $2(2)$ & $2(2)$ & $0(0)$ & $0(0)$ \\
\hline \multicolumn{5}{|c|}{ Hand therapy $(n=47)$} \\
\hline Yes & $40(85)$ & $35(88)$ & $4(80)$ & $1(50)$ \\
\hline No & $7(15)$ & $5(12)$ & $1(20)$ & $1(50)$ \\
\hline \multicolumn{5}{|c|}{ Immobilization type $(n=47)$} \\
\hline Cast & $17(36)$ & $16(40)$ & $1(20)$ & $0(0)$ \\
\hline Splint & $30(64)$ & $24(60)$ & $4(80)$ & $2(100)$ \\
\hline $\begin{array}{l}\text { Immobilization } \\
\text { duration, weeks, } \\
\text { mean }\end{array}$ & 4.86 & 4.44 & 4.7 & 4 \\
\hline
\end{tabular}

Data presented as $n$ (\%) unless otherwise indicated. APL Abductor pollicis longus; ASSH TAM American Society for Surgery of the Hand Total Active Motion score; D Digit; FDP Flexor digitorum profundus; FDS Flexor digitorum superficialis; FPL Flexor pollicis longus

size. Additionally, an epitendinous repair can clean the repair edges and increase the repair strength by $50 \%$ (13). Our results are in contrast to these tenets because the majority of our patients experienced excellent results after flexor tendon repair using a modified Kessler or figure-of-eight repair without epitendinous repair. 
TABLE 3

Demographic and outcome data for patients requiring a second procedure $(n=5)$

\begin{tabular}{|c|c|c|c|c|c|}
\hline & \multicolumn{5}{|c|}{ Patient } \\
\hline & 1 & 2 & 3 & 4 & 5 \\
\hline Second procedure & Re-repair & Tenolysis & $\begin{array}{l}\text { Two-stage tendon } \\
\text { reconstruction }\end{array}$ & Suture granuloma & Tenolysis \\
\hline Sex & Male & Female & Male & Female & Male \\
\hline Age, months & 36 & 144 & 154 & 155 & 179 \\
\hline Mechanism of injury & Glass & Knife & Knife & Knife & Knife \\
\hline Side (right/left) & Right & Right & Right & Right & Left \\
\hline Digits involved, $\mathrm{n}$ & 2 & $2,3,4$ & 3,4 & 4 & 2 \\
\hline Zone & III & II & 1 & II & II \\
\hline Tendons involved & FDS, FDP & $\mathrm{FDP} \times 3$ & FDS + FDP $\times 2$ & FDP, FDS & FDP, FDS \\
\hline First repair suture & $\begin{array}{l}\text { 5-0 prolene, modified } \\
\text { Kessler }\end{array}$ & $\begin{array}{c}\text { 4-0 prolene, modified } \\
\text { Kessler and } \\
\text { figure-of-eight }\end{array}$ & $\begin{array}{l}\text { 4-0 prolene, modified } \\
\text { Kessler }\end{array}$ & $\begin{array}{c}\text { 4-0 prolene, modified } \\
\text { Kessler }\end{array}$ & $\begin{array}{l}\text { 4-0 prolene, } \\
\text { figure-of-eight }\end{array}$ \\
\hline Epitendinous repair & No & No & Yes & No & No \\
\hline Hand therapy after first procedure & No & Yes & Yes & Yes & Yes \\
\hline Immobilization & Cast for 3.5 weeks & Splint for 4 weeks & Splint for 4 weeks & Splint for 4 weeks & Splint for 8 weeks \\
\hline ASSH TAM score at 1 year (\%) & 100 & 100 & 100 & 100 & 100 \\
\hline
\end{tabular}

ASSH TAM American Society for Surgery of the Hand Total Active Motion score; FDS Flexor digitorum superficialis; FDP Flexor digitorum profundus

The inability to increase the number of strands across a repair site is related to the smaller tendon size in children. A recent study also showed this discrepancy in adults; this study compared flexor tendon repairs of the index and small finger, suggesting that the smaller size of the small finger tendon makes it unable to accommodate the bulge of repair, leading to poorer results (14). Another series showed that a sixstrand profundus-only repair using three figure-of-eight stitches was possible in children younger than two years of age, but that the repair was bulky and required 'venting' of the pulley system. Although stronger, this technique would make it impossible to repair both tendons without pulley loss (15). Other authors showed no significant difference between two- and four-strand repairs (3); this was consistent with another group that found a slight increase in rupture rate with two-strand repairs (2). These results were not statistically significant, which may be due to insufficient power. Our findings suggest that a simple, strong core tendon repair without epitendinous repair yields excellent results in the pediatric population.

\section{Rehabilitation}

Adult studies have shown that early range of motion decreases extrinsic healing and prevents adhesions leading to improved functional outcomes (4). The literature on pediatric tendon repair shows that children completely immobilized for up to four weeks experience no decline in functional outcome, suggesting that early postoperative hand therapy protocols are not necessary $(2,7,13,14,16)$. Our results confirm this: the great majority of our patients were immobilized for four weeks and reached a TAM score of $100 \%$ at one year postoperatively. We agree with previous literature that four weeks of immobilization after pediatric flexor tendon repair within zones I, II and III is safe in children who cannot adhere to early range of motion protocols. It has been suggested that the superior results reported in some series may occur because children heal more rapidly, have a better blood supply, and have greater ability to remodel scars and adhesions $(2,7,10,17)$. Similarly, Masquelet and Gilbert (18), Fitoussi et al (19) and Strickland (20) determined that despite seemingly prolonged immobilization, primary repair of flexor tendon injuries in children produces better results than adults.

\section{Zone of injury}

The zone of injury and its effect on functional outcome remains a controversial topic in the pediatric population. Some studies have shown no link between zone of injury and outcome $(2,8)$, while another found that zone II injuries have worse outcomes (5). A third group studied 44 children with 58 injured digits and found that negative predictive factors include zone II injuries, multiple tendon involvement (FDS and FDP in the same digit), age younger than five years, immobilization longer than four weeks and below-elbow casting (indicating the requirement of above elbow casting) (19). Our study did not find a relationship between zone of injury and functional outcome.

\section{Outcomes}

Our study's favourable outcomes (measured using TAM score) were higher than previous pediatric studies. This is likely due to the fact that the majority of our patient population had zone III injuries compared with other studies with a high proportion of zone II injuries $(2,11)$. Zone III repairs have been shown to fare much better than zone II injuries, and we posit a likely cause of our positive results. Of the patients requiring a second procedure, no link was found among outcome, cause, location, repair, rehabilitation protocol or zone of injury. Similarly, Elhassan et al (5) studied 41 digit injuries in 35 patients involving zones I and II. Unlike studies of adult flexor tendon repair, this group found that excellent or good results occurred in all patients independent of timing of repair (immediate versus delayed), age, suture technique and postoperative range of motion protocol. Interestingly, these data would suggest that there are limited predictive variables that would result in a poorer result following pediatric flexor tendon repair. We would concur with other authors in the statement that pediatric flexor tendon repairs in zones I, II and/or III are less dependent on controllable or predictable factors than in adults.

\section{Limitations}

The retrospective nature of the present study must be taken into account when examining the data and comparing it with the literature. Additionally, range of motion and TAM scores were not always recorded in charts; therefore, some data were acquired by follow-up telephone call. Finally, the method of postoperative rehabilitation was not always available or defined per a traditional protocol, making comparisons between types of rehabilitation difficult.

\section{CONCLUSION}

Pediatric flexor tendon injuries remain rare and usually involve the dominant hand holding or manipulating an object (glass or knife). In our cohort, an excellent outcome was found in $95.9 \%$ of patients 
measured using TAM scores at one-year following date of surgery. Based on our results, cast immobilization of young children for four weeks is safe and effective and does not worsen functional outcomes. Of the patients requiring a second procedure, no link was found among cause, location, repair, rehabilitation protocol or zone of injury, indicating that predictive variables for a poor outcome are limited.

\section{SUMMARY}

We found that flexor tendon repair outcomes in children are generally favourable; nevertheless, a detailed and well-powered longitudinal study is required to detect clinical variables and protocols that optimize the therapeutic ratio in children with flexor tendon injuries.

DISCLOSURES: The authors have no financial disclosures or conflicts of interest to declare.

PRESENTATION: This article was presented, in part, at the Canadian Society of Plastic Surgeons Annual Meeting, June 2012, Toronto, Ontario.

\section{REFERENCES}

1. Kato H, Minami A, Suenaga N, Iwasaki N, Kimura T. Long-term results after primary repairs of zone 2 flexor tendon lacerations in children younger than age 6 years. J Pediatr Orthop 2002;22:732-5.

2. Nietosvaara Y, Lindfors NC, Palmu S, Rautakorpi S, Ristaniemi N. Flexor tendon injuries in pediatric patients. J Hand Surg Am 2007;32:1549-57.

3. Navali AM, Rouhani A. Zone 2 Flexor tendon repair in young children: A comparative study of four-strand versus two-strand repair. J Hand Surg (Eur Vol) 2008;33:424-9.

4. Chesney A, Chauhan A, Kattan A, Farrokhyar F, Thoma A. Systematic review of flexor tendon rehabilitation protocols in zone II of the hand. Plast Reconstr Surg 2011;127:1583-92.

5. Elhassan B, Moran SL, Bravo C, Amadio P. Factors that influence the outcome of zone I and zone II flexor tendon repairs in children. J Hand Surg Am 2006;31:1661-6.

6. Herndon JH. Treatment of tendon injuries in children. Orthop Clin North Am 1976;7:717-31.
7. Berndtsson L, Ejeskar A. Zone II flexor tendon repair in children. A retrospective long term study. Scand J Plast Reconstr Surg Hand Surg 1995;29:59-64.

8. O'Connell S, Moore M, Strickland J, Fazier T, Dell P. Results of zone I and zone II flexor tendon repairs in children. J Hand Surg Am 1994;19:48-52.

9. Strickland JW, Glogovac SV. Digital function following flexor tendon repair in Zone II: A comparison of immobilization and controlled passive motion techniques. J Hand Surg Am 1980;5:537-43.

10. Tuzuner S. Results of zone II flexor tendon repair in children younger than age 6 years: Botulinum toxin type $\mathrm{A}$ administration eased cooperation during the rehabilitaion and improved outcome. J Pediatr Orthop 2004;24:629.

11. Grobbellaar A, Hudson D. Flexor tendon injuries in children. J Hand Surg 1994;19:696-8.

12. Havenhill TG, Birnie R. Pediatric flexor tendon injuries. Hand Clinics 2005;21:253-6.

13. Lehfeldt M, Ray E, Sherman R. MOC-PS(SM) CME Article: Treatment of flexor tendon laceration. Plast Reconstr Surg 2008;121(Suppl):1-12.

14. Orkar KS, Watts C, Iwuagwu FC. A comparative analysis of the outcome of flexor tendon repair in the index and little fingers: Does the little finger fare worse? J Hand Surg (Eur Vol) 2012;3:20-6.

15. Al-Qattan MM. A six-strand technique for zone II flexor-tendon repair in children younger than 2 years of age. Injury 2011;42:1262-5.

16. Friedrich H, Bäumel D. Die Behandlung von Beugesehnenverletzungen im Kindesalter [The treatment of flexor tendon injuries in children]. Handchir Mikrochir Plast Chir 2003;35:347-52.

17. Lindsay WK, McDougall EP. Direct digital flexor tendon repair. Plast Reconstr Surg Transplant Bull 1960;26:613-21.

18. Masquelet AC, Gilbert A. [Recent injuries of finger flexor tendons in children]. Rev Chir Orthop Reparatrice Appar Mot 1985;71:587-93.

19. Fitoussi F, Lebellec Y, Frajman JM, Pennecot GF. Flexor tendon injuries in children: Factors influencing prognosis. J Pediatr Orthop 1999;19:818-21.

20. Strickland JW. Bone, nerve, and tendon injuries of the hand in children. Pediatr Clin North Am 1975;22:451-63. 